\title{
BACTERIOPHAGE TYPING OF SHIGELLA SONNEI AND ITS LIMITATIONS IN EPIDEMIOLOGICAL INVESTIGATION
}

\author{
BY G. H. TEE \\ The Public Health Laboratory, Tennis Court Road, Cambridge
}

Sonne's dysentery bacillus takes its name from Carl Sonne, the Danish worker who first produced evidence of its aetiological importance (Sonne, 1915), although this organism had probably been described a decade previously by Duval in America and recognized as a member of the dysentery group (Duval, 1904).

Some 30 years ago it was stated in a report (Medical Research Council, 1920) that Sonne's bacillus had never been isolated in England. In 1951 this organism was found in some 20,000 instances by bacteriologists in the Public Health Laboratory Service and associated laboratories.

Since little is known about the epidemiology or natural history of what has come to be called Sonne dysentery, an attempt to elucidate this is desirable. A method of differentiating strains, otherwise indistinguishable, by bacteriophage typing, which has proved so successful an aid in investigating the epidemiology of typhoid, might be equally valuable when applied to the investigation of Sonne dysentery. Such a method was first described by Hammarström (1947) in Stockholm, who reported that by using a battery of unadapted test bacteriophages at their appropriate strengths he had been abie to classify strains of Shigella sonnei isolated in Sweden by the reaction patterns produced. A fuller description of this investigation was published 2 years later (Hammarström, 1949).

At the end of 1948 work was begun in order to find out whether a similar method could be devised using bacteriophages and strains of Sh. sonnei isolated in this country and whether, if it could, such a method would have any practical value. In this paper an abbreviated account of this work is given.

\section{MATERIAL}

(1) Source

A. Shigella sonnei strains

272 strains were obtained over about 3 years by culture of all routine specimens of faeces examined in the Public Health Laboratory at Cambridge. 557 strains, 551 from patients and 6 from water, were obtained from eleven regions where Sonne dysentery was prevalent. The total number examined was therefore 829, their distribution being shown in Table 1.

\section{(2) Identification}

The criteria for identification as $S h$. sonnei were $(a)$ colonial morphology, $(b)$ biochemical reactions, $(c)$ motility, and $(d)$ agglutination.

(a) On MacConkey's agar, incubated for $18 \mathrm{hr}$. at $37^{\circ} \mathrm{C}$., two colonial forms are found. 
(1) A non-lactose fermenting colony about $2.0 \mathrm{~mm}$. in diameter; low dome-shaped with slight umbonation; grey-white colour by reflected light but rather browncoloured by transmitted light when viewed with a hand-lens of $\times 8$ magnification; entire edge; smooth shiny surface; soft consistency; easily emulsified.

\begin{tabular}{|c|c|c|c|c|c|}
\hline Region & $\begin{array}{l}\text { No. of } \\
\text { strains }\end{array}$ & $\begin{array}{c}\text { Per- } \\
\text { centage } \\
\text { of total }\end{array}$ & Region & $\begin{array}{l}\text { No. of } \\
\text { strains }\end{array}$ & $\begin{array}{c}\text { Per- } \\
\text { centage } \\
\text { of total }\end{array}$ \\
\hline Birmingham & 1 & $0 \cdot 1$ & Newcastle & 23 & $\mathbf{2} \cdot \mathbf{8}$ \\
\hline Cambridge & 272 & $32 \cdot 8$ & Newport, Mon. & 18 & $2 \cdot 1$ \\
\hline Dorchester & 12 & $1 \cdot 4$ & Northallerton & 25 & $3 \cdot 0$ \\
\hline Leicester & 72 & $8 \cdot 7$ & Norwich & 17 & $2 \cdot 0$ \\
\hline Luton & 23 & $2 \cdot 8$ & Nottingham & 4 & 0.5 \\
\hline Manchester & 357 & $43 \cdot 2$ & Oxford & 5 & $0 \cdot 6$ \\
\hline
\end{tabular}

(2) A non-lactose fermenting colony often 4-5 $\mathbf{~ m m}$. in diameter; colourless; flat; irregular edge; matt surface; soft consistency; easily emulsified. This form is usually found more readily when the medium has been well dried before inoculation.

Colonies of type (1) have been termed Smooth; those of type (2) being called Rough. For phage-typing purposes, cultures of the Rough kind (2) have been used exclusively. The Rough kind corresponds to the phase II of Wheeler \& Mickle (1945).

(b) Biochemical reactions. Sugar cultures were incubated at $37^{\circ} \mathrm{C}$. for 10 days in screw-capped bottles or sealed tubes. As a rule, glucose and mannitol were fermented overnight with the production of acid but no gas. Lactose and sucrose showed a late colour change. Salicin, sorbitol and dulcitol were not fermented. Indole was not produced after growth for $48 \mathrm{hr}$. in peptone water prepared with Evans's peptone.

(c) All strains were non-motile after incubation at $37^{\circ} \mathrm{C}$. for 10 days in Craigie tubes.

(d) Overnight broth cultures washed and diluted with normal saline to a standard of about 250 million bacteria per ml. agglutinated with Standards Laboratory antiserum $(\mathrm{S}+\mathrm{R})$ at $52^{\circ} \mathrm{C}$. in $2 \mathrm{hr}$. to a titre of 1 in 250 .

No strain was accepted as $S h$. sonnei unless it conformed with these criteria.

All cultures were stored on Dorset's egg medium at room temperature in the dark. Cultures were usually phage-typed within 2 days of identification.

\section{B. Bacteriophages}

Faeces of man and the pig and sewage effluent were examined by plating out glucose-broth suspensions, previously heated at $60^{\circ} \mathrm{C}$. for $30 \mathrm{~min}$., upon an agar plate prepared with a 'lawn' of non-lysogenic Sh. sonnei. In addition, lysogenic strains of Sh. sonnei were obtained by the cross-culture method of Fisk (1942).

When a plaque was found, some of the agar beneath and some of the culture surrounding it were picked with a wire into glucose broth, which was incubated at $37^{\circ} \mathrm{C}$. for about $18 \mathrm{hr}$. and then centrifuged. The supernatant broth was heated at $60^{\circ} \mathrm{C}$. for $30 \mathrm{~min}$. in a water-bath and again plated. The final preparation was the result of five such serial single-plaque transfers. 
Strong preparations were made by inoculating an agar plate, using a bent glass rod, with the sensitive strain to which a few drops of dilute bacteriophage preparation were added at the time of spreading. Confluent plaques appeared after incubation at $37^{\circ} \mathrm{C}$. for $18 \mathrm{hr}$. The growth was then washed off in $3 \mathrm{ml}$. glucose broth, centrifuged, and the supernatant heated at $60^{\circ} \mathrm{C}$. for $30 \mathrm{~min}$. All preparations were stored at $4^{\circ} \mathrm{C}$. in screw-topped bottles.

\section{TYPING TECHNIQUE}

\section{Media}

Hartley's digest broth with $1 \%$ glucose added was used for fluid cultures. Nutrient agar was prepared, in a batch large enough to last throughout the work, from Hartley's digest broth (without glucose) and $1.25 \%$ Davis New Zealand agar, final $\mathrm{pH} 7 \cdot 4$.

\section{Test dilutions of bacteriophage preparations}

Serial tenfold dilutions of strong bacteriophage in $1 \%$ glucose broth were titrated. The test dilution chosen was that at which, under standard test conditions, confluent lysis appeared on the sensitive indicator strain and no reaction on the insensitive test strain. Test dilutions were usually of the order 1 in $10^{5}$.

\section{Setting up the plate test}

Ten bacteriophages were used for typing. About $0.5 \mathrm{ml}$. of an $18 \mathrm{hr}$. broth culture of the strain to be tested was spread on a well-dried agar plate with a glass spreader to form a 'lawn'. Not less than $15 \mathrm{~min}$. afterwards, during which time the agar surface had dried, one drop of each of the ten test bacteriophage preparations was dropped upon it in the appropriate position from a ' 50 -drop' pipette.

When dry, the prepared plate was incubated at $37^{\circ} \mathrm{C}$. for $4 \frac{1}{2} \mathrm{hr}$., and then read. Reactions showing confluent lysis were recorded as positive, others as negative.

\section{The typing scheme}

The typing scheme is shown in Table 2. All types designated A are resistant to phage I; those designated $B$ are resistant to phage II, but are lysed by phage I; those designated $\mathrm{C}$ are resistant to phage III, but are lysed by phages $\mathrm{I}$ and II, and so on. Phage-type $\mathrm{L}$ is lysed by all ten test phages.

Each alphabetical group is subdivided into types having arabic numbers. The results of phage action being recorded as plus or minus reading the plate from $\mathrm{I}$ to $\mathrm{X}$, it was found simplest to designate the types according to the position of the first negative reaction within each group. Thus, of two strains in a similar alphabetical group that having a negative reaction to a phage of lower roman numeral was designated by a lower arabic number. An example will make this clear. Types E 1 and E 2 have identical reactions to phages I to $\mathrm{V}$, being group $\mathrm{E}$. They differ only in their reaction to phage $\mathrm{X}$, the resistant strain being type $\mathrm{E} 1$, the sensitive one being type $\mathrm{E} 2$ (see Table 2). A type resistant to phage VII or to any phage in the series VIII to $\mathrm{X}$, will be placed before one which is lysed by this phage. 
At first sight this seems an unnecessarily complex scheme, but in practice the correct type for a result which has been obtained previously can be read off at a glance, and speedy classification of many results is possible.

Table 2. The typing scheme

\begin{tabular}{lccccccccccc}
\multicolumn{10}{c}{ Phage } \\
Type & I & II & III & IV & V & VI & VII & VIII & IX & X & \\
A 4 & - & - & + & - & - & + & + & + & + & + & Confirmed \\
A 12 & - & - & + & + & - & + & - & - & - & + & Confirmed \\
A 15 & - & + & - & + & + & + & + & + & + & - & $\cdot$ \\
B 1 & + & - & - & - & + & - & - & - & - & - & $\cdot$ \\
B 2 & + & - & + & - & + & - & - & - & - & - & $\cdot$ \\
B 5 & + & - & + & + & + & + & - & - & - & + & $\cdot$ \\
C 1 & + & + & - & - & + & - & - & - & - & - &. \\
C 3 & + & + & - & - & + & + & + & + & + & + & Confirmed \\
C6 & + & + & - & + & + & - & - & - & - & + & Confirmed \\
C 8 & + & + & - & + & + & - & + & + & + & + & Confirmed \\
C9 & + & + & - & + & + & + & + & + & + & - & Confirmed \\
C 10 & + & + & - & + & + & + & + & + & + & + & Confirmed \\
D2 & + & + & + & - & + & - & - & - & - & + &. \\
E 1 & + & + & + & + & - & + & - & - & - & - & \\
E 2 & + & + & + & + & - & + & - & - & - & + & Confirmed \\
E 4 & + & + & + & + & - & + & + & + & + & + & Confirmed \\
F 1 & + & + & + & + & + & - & + & + & + & + & Confirmed \\
G 2 & + & + & + & + & + & + & - & - & - & + & Confirmed \\
K & + & + & + & + & + & + & + & + & + & - & Confirmed \\
L & + & + & + & + & + & + & + & + & + & + & Confirmed
\end{tabular}

\section{RESULTS}

As shown in Table 3, 829 strains were classified into twenty phage-types of which thirteen were confirmed, being found more than once, the remaining seven provisional types occurring only in single instances and therefore being unconfirmed.

The greatest variety of phage-types was found in the Cambridge region where seven confirmed types were found among 272 strains examined, whereas only four confirmed types were found among 357 strains from Manchester.

Of the thirteen confirmed phage-types, type $\mathrm{L}$ was by far the commonest, comprising 613 out of a total of 829 strains (74\%). This phage-type was found in thirty-eight out of forty-seven outbreaks in which the type was uniform; the nine other outbreaks in which the phage-type was uniform were associated with seven different phage-types.

In five outbreaks the phage-types were not uniform, that is to say more than one type was found in each of five outbreaks.

\section{DISCUSSION}

For classification of an organism by phage-typing to be reliable, phage-types must be stable both in vitro and in vivo. The phage-types here described were stable during laboratory storage.

In forty-seven out of fifty-two instances, classification by epidemiological evidence of similarity and by the results of phage-typing agreed. Because Sonne dysentery 
was prevalent at certain periods during this investigation, it is not surprising to find more than one type in an outbreak which appeared on epidemiological evidence to be uniform. Of the five outbreaks not of uniform type, two can be presumed to be true mixed infections, two were family infections and the fifth occurred among a hospital nursing staff.

Table 3. Regional distribution of phage-types

(Numbers refer to the number of strains of each type found.)

Phage-type... A4*A 12* A 15B 1 B2 B 5 C1 C3*C6* C8*C9* C10* D2 E 1 E2* E4* F 1* G2* K* L* types Region

\begin{tabular}{|c|c|c|c|c|c|c|c|c|c|c|c|c|c|c|c|c|c|c|c|c|c|}
\hline Birmingham & . & $\cdot$ & . & . & . & - & . & • & . & . & . & - & - & . & . & • & & . & . & 1 & 1 \\
\hline Cambridge & . & 2 & 1 & . & 1 & . & 1 & . & . & . & 18 & 5 & 1 & 1 & $\mathbf{1}$ & . & 22 & . & 32 & 187 & 272 \\
\hline Dorchester & . & . & . & 1 & . & . & . & . & . & . & 9 & $\mathbf{1}$ & . & . & . & . & . & . & $\mathbf{l}$ & $\cdot$ & 12 \\
\hline Leicester & . & . & . & . & . & 1 & . & . & . & . & 3 & . & . & . & 8 & . & . & . & 1 & 59 & 72 \\
\hline Luton & . & . & . & . & . & . & . & . & . & . & . & 1 & . & . & . & 2 & . & 9 & - & 11 & 23 \\
\hline Manchester & . & . & . & . & . & . & . & . & . & . & 1 & . & . & . & 15 & . & . & 24 & . & 317 & 357 \\
\hline Newcastle & . & . & . & . & . & . & . & . & . & 17 & 1 & . & . & . & . & . & . & . & . & 5 & 23 \\
\hline Newport & . & . & . & . & . & . & . & 11 & . & . & . & . & . & . & . & . & . & 7 & . & . & 18 \\
\hline Northallerton & . & . & . & . & . & . & . & - & . & . & . & . & . & . & . & . & . & . & 2 & 23 & 25 \\
\hline Norwich & . & . & . & . & . & . & . & . & 9 & . & . & . & . & . & . & . & . & . & . & 8 & 17 \\
\hline Nottingham & 2 & . & - & . & . & . & . & . & . & . & . & . & . & . & . & . & . & . & . & 2 & 4 \\
\hline Oxford & . & . & . & . & . & . & . & . & . & . & . & 4 & . & . & . & . & . & . & 1 & . & 5 \\
\hline Total & 2 & 2 & 1 & 1 & 1 & 1 & 1 & 11 & 9 & 17 & 32 & 11 & 1 & 1 & 24 & 2 & 22 & 40 & 37 & 613 & 829 \\
\hline
\end{tabular}

Table 4. Outbreaks with uniform phage-type

\begin{tabular}{|c|c|c|c|c|c|}
\hline Region & Phage-t & $\begin{array}{l}\text { No. of } \\
\text { outbreaks }\end{array}$ & Region & Phage-1 & $\begin{array}{l}\text { o. of } \\
\text { breaks }\end{array}$ \\
\hline Manchester & $\begin{array}{l}\mathrm{L} \\
\mathrm{E} 2\end{array}$ & $\begin{array}{r}16 \\
2\end{array}$ & Newport, Mon. & $\begin{array}{l}\mathrm{C} 3 \\
\mathrm{G} 2\end{array}$ & $\begin{array}{l}1 \\
1\end{array}$ \\
\hline Cambridge & $\begin{array}{l}\mathbf{L} \\
\mathbf{K}\end{array}$ & $\begin{array}{r}14 \\
2\end{array}$ & Newcastle & $\begin{array}{l}\mathrm{L} \\
\mathrm{C} 8\end{array}$ & $\begin{array}{l}1 \\
1\end{array}$ \\
\hline Leicester & $\begin{array}{l}\mathrm{L} \\
\mathrm{Cg}\end{array}$ & $\begin{array}{l}4 \\
1\end{array}$ & $\begin{array}{l}\text { Norwich } \\
\text { Northallerton }\end{array}$ & $\begin{array}{l}\mathrm{L} \\
\mathbf{L}\end{array}$ & $\begin{array}{l}1 \\
1\end{array}$ \\
\hline Luton & $\begin{array}{l}\mathrm{L} \\
\mathrm{G} 2\end{array}$ & $\begin{array}{l}1 \\
1\end{array}$ & & & \\
\hline
\end{tabular}

The term 'outbreak' is here used to denote a focus in which two or more cases occur which are thought, on epidemiological evidence, to be related.

Strains of Sh. sonnei seem likely to be of similar type when cases occur in a family or household within a short time. This was so in sixteen out of eighteen family outbreaks, from which altogether $\mathbf{4 7}$ strains were tested. Had more strains been examined, more mixed family outbreaks might well have been revealed.

Discrepancies between the epidemiological classification and the results of phagetyping could be explained in various ways.

\section{(a) Infections from separate sources by different types}

This explanation is possible but not probable in family outbreaks, although it may well apply to mixed infections in day-nurseries, hospital wards and the like. 


\section{(b) Infection from the same source by mixed types}

Infection from the same source by mixed types is unlikely here since, although search was made, two types were never isolated from the same patient.

\section{(c) Mistaken epidemiological classification}

Mistaken epidemiological information, though its possibility should always be borne in mind in any phage-typing investigation, is most unlikely in the instances we are considering in which small numbers of cases were observed in each outbreak making possible the taking of an accurate history.

\section{(d) Laboratory error in handling cultures}

Though few laboratory workers are immune against error-the present writer would not claim to be one of them-there was no indication that cultures had been wrongly identified. No strains of the aberrant types from other outbreaks were being handled in the laboratory at the relevant times. Results were repeatable. Personal bias in interpreting the results was eliminated by numbering each culture on receipt with a serial number, phage-typing being done with batches of ten at a time and the source being unknown until after the result was recorded.

\section{(e) Change of type in vivo}

The conclusion must therefore be that change of phage-type in vivo is the most likely explanation of the finding of multiple types, at any rate in family outbreaks.

Further evidence that this explanation is correct is forthcoming from a study of the single outbreak in which mixed types were found among the nursing staff of a hospital. There were thirteen cases among which four phage-types were distributed. When the biochemical properties of these strains were examined it was found (Tee, 1952) that the pentose, xylose, was fermented by all, acid, without gas, being produced. This property is uncommon in $S h$. sonnei strains in this country, since out of 812 strains (from 812 patients) examined biochemically, xylose fermentation was found in only $44(5.4 \%)$, although workers in Denmark and Sweden (Bojlén, 1934; Hammarström, 1949) have reported up to $14 \%$ of their strains with this property. Of these 44 xylose-fermenting strains, 40 were isolated in the Cambridge region, 31 of them during the summer months (May to August) of one year. Xylose fermentation is therefore important, because it suggests strongly that the type diversity in this outbreak was due to type instability of the original infecting strain.

This explanation would be greatly strengthened by evidence that the property of xylose fermentation remained constant in vitro, and by the demonstration that a parallel change in phage-type could be induced in the laboratory.

Xylose fermentation appears to be a constant property, for all 44 xylosefermenting strains retained it when re-examined after storage upon Dorset's egg for periods as long as a year.

An experiment was done to determine whether the phage-type of one of the xylose-fermenting strains from the nursing-staff outbreak could be transformed by picking colonies resistant to the action of certain bacteriophages. Ten colonies 
of strain 210 (type L) were examined for uniformity of their phage-type. All were alike. Resistant colonies growing upon the site of the phage $\mathrm{X}$ inoculum were then picked into broth and again typed. These gave the reaction of phage-type $\mathrm{K}$, being resistant to phage $\mathrm{X}$. Xylose fermentation was demonstrated after change of phage-type. These results show that change of type can be brought about in vitro, and it is suggested that such change may occur in nature. The evidence strongly suggests that such a change of phage-type occurred in this particular outbreak.

Change of phage-type in the field may theoretically be dependent on one or more of the following mechanisms influenced by bacteriophage.

A bacterial population may contain antigenic mutants which are resistant to lysis by certain bacteriophages. Jesaitis \& Goebel (1952) have suggested that the somatic antigen of phase II $S h$. sonnei is a receptor of certain of the T-series of bacteriophages which attack this organism, the extracted antigen inhibiting the action of these T-phages. Further, the same workers have shown that a phageresistant variant of phase II $S h$. sonnei has a type-specific antigen differing from that of the parent organism in serological specificity and chemical constitution. This variant does not inhibit three of the T-series which are inhibited by the phase II antigen (Goebel \& Jesaitis, 1952). It is clear, therefore, that a factor which selected such mutants might change the reaction of a strain to one or more typing phages, producing a type different from that of the original parent. Such a selecting factor may well be natural bacteriophage with which organisms come into contact in the intestine, the sensitive organisms being destroyed by lysis, the resistant organisms continuing to multiply, resulting in the complete replacement of the former phage-type by a different one.

There is evidence that another mechanism involving bacteriophage may be concerned. Williams Smith $(1948 a, b)$, working with staphylococci, found that some strains 'carried' the bacteriophage to which they had been made resistant and that others did not; although, as this worker pointed out, there was reason to believe that the technique of demonstrating the presence of 'carried' bacteriophage was unsatisfactory, since lysogenicity - by which its presence was determinedmight not always be revealed by the technique used. Acquired phage-resistance was shown to be responsible for the classification of some strains as different phage-types. A similar conclusion was reached by Williams Smith in respect of Salmonella thompson when typed by bacteriophages obtained from lysogenic strains (Williams Smith, 195I). It has been suggested by Scholtens (1950) that strains of $S$. paratyphi B can be typed by determining their lysogenic properties. In a study of the symbiotic bacteriophages in $S$. typhi-murium, Boyd (1950) found that about $80 \%$ of the strains isolated from human infections carried symbiotic bacteriophages. It would appear reasonable to expect, therefore, that the bacteriophages with which an organism has come into contact may condition its behaviour when examined by the phage-typing technique.

Another factor which may operate in the changing of phage-type in vivo is chemical. It has been shown (Barry \& Goebel, 1951) that the somatic antigen of phase II Shigella sonnei, with which some of the T-series of bacteriophages combine, is sensitive to a number of physical agents, so that the ability of the 
intact organism to combine with one of the T-phages can be impaired without affecting its combining power in respect of the other $\mathrm{T}$-phages. It would be interesting to determine by experiment whether the sulphonamides can impair the phage-adsorbing properties of $S h$. sonnei, for if they can, we might expect a difference in phage-type between strains isolated before and after sulphonamide treatment, or the isolation of mixed types after treatment. However, in the six sulphonamide-treated cases from which more than one culture was examined, the phage-type remained constant.

\section{RESULTS OF OTHER WORKERS}

Hammarström (1949), using his eleven typing phages, classified 1834 Swedish strains of $S h$. sonnei into sixty-eight phage-types, of which thirty-one were verified, being associated with more than half the strains. Outbreaks of uniform type predominated, numbering 121. There were twelve outbreaks which were not uniform during the same period (1943 to 1947).

Subsequently, workers in three other countries have reported their results using Hammarström's set of typing phages.

Raška, Mališová \& Mazáček (1950) in Czechoslovakia typed 168 strains of which $50(30 \%)$ were type 3.

Mayr-Harting (1952) examined 560 strains isolated in England, of which 517 were found in the Bristol area, 43 in several other places. $455(81 \%)$ of the total were type 3. The type was uniform in seven out of ten outbreaks. From her experimental evidence of type instability in vitro, this worker suggests that type instability in vivo may occur.

Ludford (1953), typing strains isolated in Australia and Tasmania, found that the predominant strain was type $19 ; 207$ of 244 cultures $(85 \%$ ) belonging to this type. Only 10 type 3 strains were found. Ludford concluded that phage-typing by Hammarström's method is of considerable value when correlated with other epidemiological evidence.

\section{CONCLUSIONS}

To sum up, it can be said that, while these results confirm the contention of Hammarström $(1947,1949)$ that phage-typing of $S h$. sonnei strains is possible, the practical value of this procedure to the epidemiologist is slight. For this there are three reasons. First, most strains are of the same phage-type, so that it is often impossible to identify different sources of infection, strains of similar phage-type being not necessarily associated. Secondly, type-instability in vivo makes it impossible to be certain that strains of different phage-type are not associated epidemiologically, such strains not necessarily being derived from separate sources. Thirdly, the importance of the chronic carrier of $S h$. sonnei as a source of infection in the community has not yet been assessed.

\section{SUMMARY}

An investigation into the classification of strains of Shigella sonnei by the method of phage-typing (using unadapted bacteriophages) is described. 
829 strains, obtained during 3 years from twelve regions in England (including Monmouthshire) were examined by a standard technique. There were fifty-two outbreaks (involving 587 strains) from which two or more strains were isolated.

Results confirmed the finding by Hammarström in Sweden that such classification was possible, strains falling into twenty phage-types of which thirteen were found more than once. All strains were typable, $74 \%$ belonging to the same type. In forty-seven outbreaks the phage-type was uniform, the commonest type occurring in thirty-eight of these. In five outbreaks the phage-type was not uniform.

It is concluded that this method of phage-typing, because of evidence of type instability and because the majority of strains belong to the same phage-type, has little practical value as a routine procedure in the control of Sonne dysentery in this country.

The following acknowledgements are gratefully made: to Dr R.M. Fry, Director, Public Health Laboratory, Cambridge, for laboratory facilities and advice; to Dr Ernst Hammarström, State Serum Institute, Stockholm, and the several bacteriologists who have assisted by sending cultures; to Mr V. Rolfe, F.I.M.L.T., and his assistants for help in preparing media; to Miss Margaret Strickland for typing the manuscript.

\section{REFERENCES}

Barry, G. T. \& GoebeL, W. F. (1951). J. exp. Med. 94, 399.

BoJlén, K. (1934). Thesis: Dysentery in Denmark. Copenhagen.

Boyd, J. S. K. (1950). J. Path. Bact. 62, 501.

Duval, C. W. (1904). J. Amer. med. Ass. 43, 381.

FISK, R. T. (1942). J. infect. Dis. 71, 153.

Goebed, W. F. \& Jesaitis, M. A. (1952). J. exp. Med. 96, 425.

HaMmarström, E. (1947). Lancet, i, 102.

Hammarström, E. (1949). Acta med. scand. 133 (Suppl. No. 223).

Jesattis, M. A. \& Goebel, W. F. (1952). J. exp. Med. 96, 409.

LUdFord, C. G. (1953). Aust. J. exp. Biol. med. Sci. 31, 545.

MaYr-HaRting, A. (1952). J.gen. Microbiol. 7, 382.

Medical Research Council (1920). Spec. Rep. Ser. med. Res. Coun., Lond., no. 51, p. 54.

RAŠKA, K., MALIŠová, V. \& MAZÁČEK, M. (1950). Čas. Lék. čes, 89, 835.

Scholtens, R. T. (1950). Leeuwenhoek ned. Tijdschr, 16, 256.

SoNNE, C. (1915). Zbl. Bakt. (Abt. 1), 75, 408.

TEE, G. H. (1952). Mon. Bull. Minist. Hlth Lab. Serv. 11, 68.

WhEELER, K. \& MrOKLE, F. L. (1945). J. Immunol. 51, 257.

Writrams SMTTH, H. (1948a). J. Hyg., Camb., 46, 74.

Wirliams SмтTH, H. (1948b). J. Hyg., Camb., 46, 82.

Wirliams SмIтH, H. (1951). J. gen. Microbiol. 5, 472.

(MS. received for publication 15. Ix. 54) 